Cumhuriyet International Journal of Education-CIJE

e-ISSN: 2147-1606

Vol 5 (2), 2016, 9 - 22

\title{
Examining Of The Change In Mental Models About Scientific Value In Terms Of Different Some Variables
}

\author{
Ufuk SÖZCÜ1, A. Oğuzhan KILDAN², Duran AYDINÖZÜ³ , B. Ünal İBRET4
}

\section{Summary}

\section{INTRODUCTION}

Since mental models are internal representations, they examine what students know, how they create knowledge in their minds, determine their knowledge level and uncover the existing misconception. Social science is a field which contains many disciplines so learning domains and units of social science include many concepts. It is supposed that mental model studies will contribute to these concepts becoming permanent in students' minds. In this context, the purpose of research is to seek an answer for the following question: Is there a marked difference between mental models of seventh-grade students before and after learning depending on the variables (gender, course grade, educational backgrounds of parents and income level).

\section{METHODOLOGY}

\section{The Model of the Study}

In the research, case study model was used to detect the mental models of students. In addition, receiving two-stage data and pre-experimental design with one group pre-test and post-test which does not contain any control group were used as a quantitative research model. The study group of research includes 311 seventh-grade students who study in three different secondary schools in the city center of Kastamonu.

\section{Data Collection and Analysis}

It was asked students to create a metaphor, draw a picture or a caricature with the reasons related to being scientific value in order to determine the mental models of students. Taking the studies of Kurnaz, Kildan and Ahi (2013) as references, findings recovered in metaphor and drawing parts were compared and the mental models of students related to being scientific value were determined. In other words, by analyzing the metaphors and drawings the mental models of students were determined within categories determined with the help of experts. The differentiation of these mental models in pre-test and post-test was determined by using Chi-square test which is one of the nonparametric statistical methods and suitable for quantitative method of research in Statistical Package for Social Sciences (SPSS).

\section{FINDINGS}

No difference has been pointed out about the mental models of the students according to their gender, a significance difference has been found out in their social studies lesson grades. While a significant difference has been found out in the mental models according to education background of the parents and income level in the pre-test, no significant difference has been found out in between these variants in the post-test.

\section{CONCLUSION}

The following results were found from the data which was obtained through the data collection tool and statistical package. Gender does not have an impact on mental models. A 
significant difference has been seen between social studies grades and mental models of students in both pre-test and post-test.

While students whose parents have a better educational backgrounds have a higher mental model ratio before teaching being scientific value, the effect of parents' educational backgrounds on mental models of students has disappeared after teaching being scientific value. Thus, it can be concluded that parents with high level of education have an influence on preparedness of students. Besides, education applications removing the difference between students should be evaluated positively .The initial significant difference which is for the benefit of students from higher income has disappeared in the post-test. This result shows that education is influential. 